\title{
MicroRNA- 137 promoter methylation in oral lichen planus and oral squamous cell carcinoma
}

\author{
Jun Dang ${ }^{1,2}$, Yong-Qian Bian ${ }^{3}$, JianYong Sun $^{3}$, Fang Chen ${ }^{1}$, Guang-Ying Dong ${ }^{1}$, Qing Liu ${ }^{1}$, Xin-Wen \\ Wang $^{1}$, Jørgen Kjems ${ }^{4}$, Shan Gao ${ }^{4}$, Qin-Tao Wang ${ }^{1}$ \\ ${ }^{1}$ Department of Periodontics and Oral Medicine, School of Stomatology Fourth Military Medical University, Xi'an, China; ${ }^{2}$ Department of \\ Stomatology, Affiliated Hospital of the Academy of Military Medical Sciences Beijing, China; ${ }^{3}$ Department of General Surgery, Xijing \\ Hospital Fourth Military Medical University, Xi'an, China; ${ }^{4}$ The Interdisciplinary Nanoscience Center (iNANO), Department of Molecular \\ Biology and Genetics, Aarhus University, Aarhus, Denmark
}

\begin{abstract}
Oral lichen planus (OLP) is a common oral mucosal disease, which is generally considered a potentially malignant lesion. To identify efficiently prognostic biomarker, we investigated the microRNA-I37 (miR-/37) promoter methylation in OLP and compared with the samples from healthy volunteers and patients with oral squamous cell carcinoma (OSCC). A total of 20 OLP and 12 patients with OSCC as well as 10 healthy subjects were subjected to $\mathrm{miR}-\mathrm{I} 37$ promoter methylation analysis using methylation-specific PCR (MSP). To address the malignancy prediction potential from miR-I37 promoter methylation status, methylation of the p/6 gene, a wellknown tumor suppressor, was investigated in the same samples. The pl6 methylation and miR-I37 promoter methylation were found to be $25 \%$ and $35 \%$ in patients with OLP, $\mathbf{5 0} \%$ and $\mathbf{5 8 . 3} \%$ in patients with OSCC, and $\mathbf{0} \%$ and $0 \%$ in healthy subjects, respectively. The differences between miR-I37 and p/6 methylation levels were statistically significant between healthy controls and patients. Methylation levels of the two promoters were also influenced by age, gender, and lesion duration. Interestingly, aberrant promoter methylation of the pl 6 and $m i R-$ I37 genes was only found in the epithelium but not in the connective tissue from patients with OLP. This raises the possibility to use miR-I37 methylation as a biomarker for malignant prediction in patients with OLP.

J Oral Pathol Med (2012)
\end{abstract}

Keywords: miR-137; oral lichen planus; oral squamous cell carcinoma; p/6; promoter methylation

Correspondence: Qin-Tao Wang, DDS, Department of Periodontics and Oral Medicine, School of Stomatology, Fourth Military Medical University, Xi'an 710032, China. Tel: 8629 84776096, Fax: 8629 83223047,

E-mail: qintaowang@hotmail.com

Shan Gao, $\mathrm{PhD}$, The Interdisciplinary Nanoscience Center (iNANO) and Department of Molecular Biology and Genetics, Aarhus University, C.F. Møllers Alle, Building 1130, 8000 Aarhus C, Denmark.

Tel: 0045 87154975, Fax: 004586196500 , E-mail: shg@mb.au.dk Accepted for publication September 20, 2012

\section{Introduction}

Oral lichen planus (OLP) is one of the most common chronic oral mucosal diseases, and females have more liability to it $(1,2)$. Oral lichen planus is classified as a potentially malignant disorder by WHO (1). However, a controversy still exists in literature regarding the malignant potential of OLP (3-5). In recent years, some retrospective studies revealed a frequency of malignant transformation from 1.5 to $6.4 \%$, with a follow-up period of at least 6 months (6-9). These facts suggest that patients with OLP have a risk of malignancy, but the mechanisms of the development of malignancy have not been clearly described yet, especially there is a lack of efficient biomarkers to predict the malignant outcome.

DNA promoter methylation is an epigenetic change that happens frequently to regulate the expressions of genes (10). Recently, multiple studies have showed that DNA promoter methylation usually is an early event in carcinogenesis, including oral cancer (11-14). The pl6 gene, a well-known tumor suppressor, plays an important role in regulating the cell cycle, and it has been reported that p16 promoter methylation is mainly responsible for $p 16$ inactivation during the malignancy in many types of human cancers $(13,15)$. pl6 methylation was also detected in oral squamous cell carcinoma (OSCC) and oral pre-cancerous lesion $(16,17)$. In a prospective cohort study including 78 cases of dysplasia with a 45.8-month follow-up, the patients with p16 methylation were found undergoing malignant transformation from epithelial dysplasia more frequently than the ones with unmethylated p16 promoter (18), and it is suggested as a biomarker for the early malignant alteration in oral potentially malignant lesions, such as oral leukoplakia. However, p16 methylation in patients with OLP has not been reported.

MicroRNAs (miRNAs) are a 21-23 nucleotide-long noncoding RNA molecules that functions to regulate the expression levels of one or more target genes. For instance, in the early stage of carcinogenesis, the altered miRNA expression has already been demonstrated, and this may 
play a key role in the transformation of the cell $(19,20)$. Thus, changes in miRNA expression patterns provide a great diagnostic tool and prognostic prediction power for human cancers $(21,22)$. Candidate miRNAs with potential roles in oral cancer etiology and progression have been proposed including loss of $m i R-34 b, m i R-100, m i R-125 b$ miR-137, miR-193a, and miR-203 (19, 21-24). Usually, upregulation of a miRNA has more prediction power than negative biomarkers. Indeed, miRNA deregulation and complete silencing have been linked to a number of cancer types, accompanying with aberrant $\mathrm{CpG}$ methylation within the promoter region. $m i R-137$ gene has a wide-spread $\mathrm{CpG}$ island, and methylation of these segments has been found in OSCC (19), gastric cancer cell lines (25), and colon cancer (26). Furthermore, it has been reported that miR-137 promoter methylation could be detected in mouth rinse and saliva in patients with oral carcinomas $(27,28)$. miRNA alterations have also been also found in patients with OLP where $m i R-125$ and $27 b$ are downregulated (29), but there are no reports studying miRNA methylation in OLP. Here, we investigate the potential for miR-137 promoter methylation to serve as positive biomarkers in OLP.

During the malignant progress of oral mucosal lesions, the interaction between epithelium and underlying connective tissue has been a subject of interest. As a completely different gene methylation patterns between epithelium and connective tissue in healthy volunteers have been demonstrated previously $(14,28)$, we here designed the experiment to detect promoter methylation in epithelium and connective tissue separately. This approach enabled us to investigate the differences of methylation profiles between both kinds of tissue and help us to understand their role in the possible malignant transformation progression for OLP.

We discovered that methylation of miR-137 and p16 occured in patients with OLP, but the frequency was lower than in patients with OSCC. Interestingly, the methylation was only found in epithelium but not in connective tissues in OLP, indicating the early malignant alteration of OLP lesion may originate from the epithelium. Our finding adds novel information to the possibility of the development OSCC from OLP and provides a novel biomarker for the malignant potential.

\section{Materials and methods}

Tissue samples

All the oral mucosa tissues were obtained from School of Stomatology, Fourth Military Medical University (FMMU), Xi' an, China, between October 2010 and August 2012. The samples were collected from 20 patients with OLP (the duration of disease from 0.5 to 12 years, average 5.6 years), 12 patients with OSCC, and 10 healthy volunteers (Table 1). Tissues were separated into two parts, one was stored in $-20^{\circ} \mathrm{C}$ for DNA extraction, and another one was used for histopathological diagnosis. Final diagnoses were made based on the clinical and pathological characterizations according to the criteria made by WHO (30). There is no one with epithelial dysplasia in this group of patients with OLP and no LP lesion from other area of their body. All the patients were untreated before sample collection. Clinical data from the patients were collected at the time of
Table 1 Description of the study population

\begin{tabular}{|c|c|c|c|}
\hline & $\begin{array}{l}\text { OSCC, } \\
n=12\end{array}$ & $\begin{array}{c}O L P, \\
n=20\end{array}$ & $\begin{array}{l}H M^{a} \\
n=10\end{array}$ \\
\hline Age, mean years & 60.4 & 49.6 & 27.8 \\
\hline \multicolumn{4}{|l|}{ Gender } \\
\hline Male & 8 & 8 & 5 \\
\hline Female & 4 & 12 & 5 \\
\hline \multicolumn{4}{|l|}{ Family history } \\
\hline Yes & 0 & 0 & 0 \\
\hline No & 12 & 20 & 10 \\
\hline \multicolumn{4}{|l|}{ Years smoking } \\
\hline Never & 4 & 13 & 7 \\
\hline$<10$ years & 0 & 2 & 2 \\
\hline$>10$ years & 4 & 2 & 1 \\
\hline$>20$ years & 4 & 3 & 0 \\
\hline \multicolumn{4}{|l|}{ Alcohol Use ${ }^{\text {b }}$} \\
\hline Never & 8 & 17 & 10 \\
\hline A little & 4 & 3 & 0 \\
\hline Much & 0 & 0 & 0 \\
\hline Combined tobacco/alcohol use & 4 & 1 & 0 \\
\hline \multicolumn{4}{|l|}{ Wear dentures } \\
\hline Yes & 3 & 4 & 0 \\
\hline No & 9 & 16 & 10 \\
\hline \multicolumn{4}{|l|}{ Lesion site (Biopsy) } \\
\hline Buccal & 5 & 16 & - \\
\hline Tongue & 6 & 4 & - \\
\hline Palate & 1 & 0 & - \\
\hline \multicolumn{4}{|c|}{ Lesion also in other sites in the mouth } \\
\hline Yes & & 9 & \\
\hline No & & 11 & \\
\hline \multicolumn{4}{|l|}{ Duration period } \\
\hline$<5$ years & - & 9 & - \\
\hline $5-10$ years & - & 6 & - \\
\hline$>10$ years & - & 5 & - \\
\hline \multicolumn{4}{|l|}{ Stage of tumor } \\
\hline I & 7 & - & - \\
\hline II & 5 & - & - \\
\hline
\end{tabular}

${ }^{a}$ Healthy Mucosa.

${ }^{\mathrm{b}} \mathrm{A}$ little: one drink a week; Much: one drink every day. One drink is considered to be one beer (12 oz), one glass of wine (5 oz), or one shot of liquor $(1.5 \mathrm{oz})$.

enrollment. The protocol has been approved by the Ethics Committee of the School of Stomatology, FMMU.

Tissue separation and DNA extraction

Mucosal tissues from patients with OLP and healthy volunteers were separated into epithelium and connective tissue in $2 \mathrm{mM}$ EDTA buffer $(\mathrm{pH}=7.2$, containing EDTA, $\mathrm{NaCl}, \mathrm{KCl}, \mathrm{Na}_{2} \mathrm{HPO}_{4}$, and $\mathrm{KH}_{2} \mathrm{PO}_{4}$ ) for 1-h incubation at $37^{\circ} \mathrm{C}(31)$. DNA was extracted by routine method using a TIANamp Genomic DNA kit (Tiangen, Beijing, China).

\section{Methylation analysis}

Genomic DNA was treated with sodium bisulfite as described elsewhere (32). Methylation-specific polymerase chain reaction (MSP) was used for the analysis of p16 and miR-137 promoter methylation, and then,the PCR products were resolved on $2 \%$ agarose gel. The primer sequences used to assess p16 promoter methylation were as follows: methylated alleles - 5'-TTATTAGAGGGTGGGGCGGA TCGC-3' and 5'-GACCCCGAACCGCGACCGTAA - $3^{\prime}$ with an annealing temperature of $57^{\circ} \mathrm{C}$ and expected amplicon of $243 \mathrm{bp}$; and unmethylated alleles-5'-TTAT TAGAGGGTGGGGTGGATTGT-3' and 5'-CAACCCC 
AAACCACAACCATAA-3' with an annealing temperature of $57^{\circ} \mathrm{C}$ and expected amplicon of $243 \mathrm{bp}$ (11). The primer sequences used to assess $m i R-137$ promoter methylation were as follows: methylated alleles - 5'-GCGGTAGTAG TAGCGGTAGC-3' and 5'-ACCCGTCACCGAAAAAAA $-3^{\prime}$ with an annealing temperature of $58^{\circ} \mathrm{C}$ and expected amplicon of $86 \mathrm{bp}$; and unmethylated alleles - 5'-GGT GGTAGTAGTAGTGGTAGT-3' and 5'-TACCCATCACC AAAAAAAA-3' with an annealing temperature of $51^{\circ} \mathrm{C}$ and expected amplicon of $86 \mathrm{bp}$ (27).

Positive control of methylated PCR was included using fully methylated DNA obtained from DNA treated with SssI methyltransferase (New England Biolabs Inc., Ipswich, MA, USA).

\section{Statistical analysis}

A Student's $t$-test was used to compare the age differences between groups, and Fisher's exact test was used for comparison among categorical variables.

\section{Results}

\section{p16 gene promoter methylation status}

The p16 promoter methylation was detected in 5 of 20 patients with OLP, 6 of 12 patients with OSCC, and 0 of 10 healthy subjects. All methylation events in OLP samples were found in epithelium but not in connective tissue (Table 2). There was statistically significant difference of p16 gene promoter methylation frequency between patients with OLP or OSCC and controls $[P<0.05$ or $<0.005$, respectively]. However, no statistically significant difference was found between OLP group and OSCC group $[P>0.05]$. Representative examples of MSP for the $p 16$ gene promoter methylation were showed in Fig. 1.

Table 2 p16 and miR-137 gene promoter methylation rates in each group

\begin{tabular}{clcllr} 
& \multicolumn{2}{c}{$p 16$} & & \multicolumn{2}{c}{$m i R-137$} \\
& $M(\%)$ & $U(\%)$ & & $M(\%)$ & $U(\%)$ \\
\hline OLP & & & & & \\
Ep & $5(25)$ & $15(75)$ & & $7(35)$ & $13(65)$ \\
Cn & $0(0)$ & $20(100)$ & & $0(0)$ & $20(100)$ \\
OSCC & $6(50)$ & $6(50)$ & & $7(58.3)$ & $5(41.7)$ \\
HM & & & & & \\
Ep & $0(0)$ & $10(100)$ & & $0(0)$ & $10(100)$ \\
Cn & $0(0)$ & $10(100)$ & & $0(0)$ & $10(100)$ \\
\hline
\end{tabular}

M, methylated; U, unmethylated; Cn, connective tissue; Ep, epithelial tissue; HM, healthy mucosa.

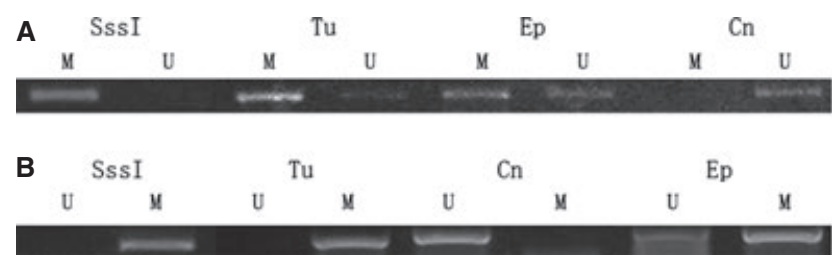

Figure 1 Examples of methylation of $p 16$ and miR-137 promoter. A: p16 promoter methylation; B: miR-137 promoter methylation. SssI, positive controls for methylated allele of two genes. M, methylated; U, unmethylated; $\mathrm{Cn}$, connective tissue; Ep, epithelium; Tu, tumor tissue.
miR-137 gene promoter methylation status

$m i R-137$ promoter methylation was detected in 7 of 20 patients with OLP, 7 of 12 patients with OSCC, and 0 of 10 of normal subjects. Similarly to $p 16$, methylation of $m i R$ 137 in OLP samples was not found in connective tissue but only in epithelium (Table 2). There were statistically significant differences in miR-137 gene methylation levels between healthy individuals and OLP group as well as OSCC group $[P<0.025$ and $<0.005$, respectively]. No statistically significant difference was found between the OLP and OSCC groups $[P>0.05]$. Representative examples of MSP for the miR-137 gene promoter methylation were also showed in Fig. 1.

\section{Correlation analysis between methylation- and disease-} associated risk factors

The significance of the associations between promoter methylation and various risk factors were analyzed using Student's $t$-test for the correlation with age and Fisher's exact test for correlations with other factors. Even with relative limited objects in the present study, we found a significant correlation of methylation of both $p 16$ and $m i R$ 137 with age $(P<0.05)$, and higher methylation frequency was in male than in female patients with OLP. Duration of disease was also associated with methylation status of the $m i R-137$ promoter methylation, which patients with OLP with a longer duration of disease $(>5$ years) demonstrated a higher methylation rate of $m i R-137(P<0.05)$. In addition, the $m i R-137$ methylation status was also correlated with alcohol use in patients with OSCC $(P<0.05)$. More details for correlation of $m i R-137$ methylation with risk factors were summarized in Table 3.

\section{Discussion}

The malignant transformation of OLP to OSCC has been recognized since 1910 (33). However, there are also some controversial reports that question its malignant potential (3-5). In this study, we investigated the alterations of two molecular biomarkers in OLP and compared with the levels in OSCC. We observed higher frequency of $m i R-137$ and p16 promoter methylation in the mucosal tissues of patients with OLP than in the mucosal tissues from healthy individuals, but the frequency was significantly lower than in patients with OSCC. Interestingly, methylation occured exclusively in epithelium in our present study; no methylation was found for either $p 16$ gene or $m i R-137$ gene in connective tissue in patients with OLP. This observation indicates tissue-specific pattern of methylation, which is in agreement with previous reports studying methylation patterns in the $P A I-1$ and $m i R-137$ promoter region in oral malignant and normal epithelium (14, 19, 28). It also indicates that the malignant alterations of OLP lesion probably initiate from epithelium and imply that studying the specific molecular alteration in epithelium may enable early detection of malignant neoplasms of epithelial origin.

In general malignant progression is accompanying the abnormal histopathological alteration, that is, epithelial dysplasia. The OLP samples in the present study did not reveal any epithelial dysplasia, indicating that the methylation may occur prior to the histological alteration during 
Table 3 Association of exposure variables with $m i R-137$ methylation status

\begin{tabular}{|c|c|c|c|c|c|c|}
\hline \multirow{2}{*}{ miR-137 } & \multicolumn{2}{|c|}{$O L P$} & \multirow[b]{2}{*}{$\mathrm{P}$-value } & \multicolumn{2}{|c|}{ OSCC } & \multirow[b]{2}{*}{$\mathrm{P}$-value } \\
\hline & $\begin{array}{c}M, \\
n=7\end{array}$ & $\begin{array}{c}U, \\
n=13\end{array}$ & & $\begin{array}{c}M, \\
n=7\end{array}$ & $\begin{array}{l}U, \\
n=5\end{array}$ & \\
\hline Age, mean years & 55.9 & 46.2 & $0.05^{\mathrm{a} *}$ & 62.4 & 57.6 & $0.2^{\mathrm{a}}$ \\
\hline \multicolumn{7}{|l|}{ Gender } \\
\hline Male & 5 & 3 & \multirow[t]{2}{*}{$0.05^{\mathrm{b} *}$} & 7 & 1 & \multirow[t]{2}{*}{$0.005^{\mathrm{b}}$} \\
\hline Female & 2 & 10 & & 0 & 4 & \\
\hline \multicolumn{7}{|l|}{ Years smoking } \\
\hline Never & 3 & 10 & \multirow[t]{4}{*}{$0.25^{\mathrm{b}}$} & 1 & 3 & \multirow[t]{4}{*}{$0.1^{\mathrm{b}}$} \\
\hline$<10$ years & 1 & 1 & & 0 & 0 & \\
\hline$>10$ years & 0 & 2 & & 2 & 2 & \\
\hline$>20$ years & 3 & 0 & & 4 & 0 & \\
\hline \multicolumn{7}{|l|}{ Alcohol use ${ }^{\mathrm{b}}$} \\
\hline Never & 5 & 12 & \multirow[t]{3}{*}{$0.25^{\mathrm{b}}$} & 3 & 5 & \multirow[t]{3}{*}{$0.05^{\mathrm{b}}$} \\
\hline A little & 2 & 1 & & 4 & 0 & \\
\hline Much & 0 & 0 & & 0 & 0 & \\
\hline $\begin{array}{l}\text { Combined tobacco/ } \\
\text { alcohol use }\end{array}$ & 1 & 0 & $0.5^{\mathrm{b}}$ & 4 & 0 & $0.1^{\mathrm{b}}$ \\
\hline Wear dentures & 2 & 2 & $>0.99^{\mathrm{b}}$ & 1 & 2 & $0.5^{\mathrm{b}}$ \\
\hline \multicolumn{7}{|l|}{ Lesion site } \\
\hline Buccal & 5 & 11 & \multirow[t]{3}{*}{$>0.99^{\mathrm{b}}$} & 2 & 3 & \multirow[t]{3}{*}{$0.9^{\mathrm{b}}$} \\
\hline Tongue & 2 & 2 & & 4 & 2 & \\
\hline Palate & 0 & 0 & & 1 & 0 & \\
\hline \multicolumn{7}{|l|}{ Duration period } \\
\hline$<5$ years & 1 & 8 & \multirow{3}{*}{$0.05^{\mathrm{b}}$} & - & - & \\
\hline $5-10$ years & 2 & 4 & & - & - & \\
\hline$>10$ years & 4 & 1 & & - & - & \\
\hline \multicolumn{7}{|l|}{ Stage of tumor } \\
\hline I & - & - & & 3 & 4 & \multirow[t]{2}{*}{$0.1^{\mathrm{b} *}$} \\
\hline II & - & - & & 4 & 1 & \\
\hline
\end{tabular}

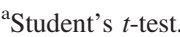

${ }^{\text {b}}$ Fisher's exact test.

*Significant correlation was also found between factors indicated and p16 methylation.

M, methylated; U, unmethylated.

progression of the disease. The similar observation has previously been reported in histologically normal epithelium adjacent to the tumor site in patients with oral carcinoma, for example, aberrant expression and mutation of p53 (34) as well as aberrant methylation of the $A B O$ (35) and DBCCRl (36) genes. In patients with OLP, the $p 53$ and $p 21$ aberrant expression was found in higher ratio than in patients with oral non-specific mucositis, suggesting that more attention should be paid to OLP for its potential role in malignant transformation (37). All those findings suggest that our promoter methylation biomarkers may be even more useful for early predication of malignancy.

In 1994, the p16 gene was demonstrated by Kamb (38) to be a tumor suppressor gene and also called multiple tumor suppressor 1 (MTS-1), and its important role in regulation of the cell cycle has been subject of numerous studies. It has clearly been demonstrated that a decline in p16 expression increases the risk of developing a variety of cancers, and aberrant promoter methylation is considered to be a common way in the inactivation of p16 $(15,39-41)$. Inactivation of $p 16$ and associated promoter methylation has been considered a robust biomarkers for oral cancer $(15,42$, 43) and other types of human cancers (44-46). In the present study, p16 promoter methylation was detected in 5 of $20(25 \%)$ patients with OLP, and 6 of $12(50 \%)$ patients with OSCC in contrast to none of normal subjects. The results indicate that the aberrant pl6 gene promoter methylation in patients with OLP may be used as an indicator for its malignant potential. This finding agrees with previous studies by others $(16,47)$ that have drawn similar conclusions in patients with oral leukoplakia accompanying with or without epithelial dysplasia.

Compared to p16, a classical biomarker, microRNAs have attracted more attention since 2006 and been reported to be hypermethylated in many types of cancer $(19,25,26)$. miRNA alterations in oral cancer have been reported, that is, $m i R-375$ was repressed, and miR-127 activated in OSCC tumors $(19,28)$. Altered expressions of $m i R-21, m i R-424$, and $m i R-137$ were also detected in OSCC $(27,48-50)$, and miRNA alterations have also been found in leukoplakia (51) and OLP (52). For example, both miRNA-146a and miRNA155 were increasingly expressed in OLP lesions (52). In a comparison between patients with OLP and healthy controls, 46 miRNAs were found to be differentially expressed with more than 2-fold change, including 8 upregulated and 38 downregulated miRNAs (53). OSCC-correlated upregulation of $m i R-21, m i R-223$, and $m i R-143$ was also found in OLP (54). $m i R-137$ is located on human chromosome $1 \mathrm{p} 22$ and shown to have tumor suppressor potential in several types of solid tumors, and miR-137 methylation is commonly observed in human cancers $(27,55)$, including OSCC $(19,28)$. In this study, $m i R-137$ promoter methylation was found positively in 7 of $20(35 \%)$ patients with OLP and 7 of $12(58.3 \%)$ patients with OSCC. Our data indicate that methylation of the $m i R-137$ promoter may have a potential to be served as a biomarker for malignant predication in patients with OLP during the follow-up. However, the difference was not statistically significant between OLP group and OSCC group in miR-137 promoter methylation rates due to the relative less case number.

In the analysis of gene promoter methylation-associated risk factors, we found relatively higher frequency of gene promoter methylation in aged, male patients and/or with longer duration of disease. Aging-related hypermethylation has been demonstrated in many different genes like IGF2 gene (56) and $p 21$ gene (57). Dysregulated expression of microRNAs in aging-dependent diseases has been also described (58), and it was further addressed that miR-17-92 cluster might be important regulators on the crossroads between aging and cancer (59). To exclude the impact of age on methylation in malignancy, age-matched control group may be necessary to be included, but this is practically a difficult task. For gender-related DNA methylation, there are also several reports demonstrating female predominant gene methylation, such as MTAP (60) in gastric cancer, $p 14^{a r f}(61)$ in colorectal cancer, and $\mathrm{CDH1}$ (62) in lung cancer. Male-correlated methylation has also been reported, that is, RASSF1A in lung cancer (62-64). This could be influenced by sex hormones or by physiological differences between the target organs. Promoter methylation of miR-137 obtained from oral rinse in patients with OSCC has previously been shown $(27,65)$ where women were found to have a five times higher risk of $m i R$ 137 methylation compared to men (27). The disagreement to our results may need to be clarified in future using an enlarged number of samples. Also, the incidence of OLP is 
generally higher in female than male. It is possible that the higher methylation frequency in males in our study may rely on other factors, for example smoking or other environmental factors. Although smoking is not associated with methylation in this study, some studies have reported an association between methylation and smoking in lung (62, 63), prostate (66), and bladder (67) cancer tissue. One recent report indicated that the methylation of multiple microRNA loci was not correlated with smoking habit for most of miRNAs analyzed in non-small-cell lung cancer patients, except for miR-124-2 and miR-124-3 (68). Epigenetic regulation of miR-34a was associated with ethanol-induced apoptosis in human hepatocytes, indicating the roles of epigenetic alteration of miRNA in alcohol-related diseases (69). It is widely accepted that alcohol/smoking can cause cancers, but whether it can influence the gene methylation rates in OLP and furthermore promote malignant transformation of OLP still needs to be uncovered. Multiple miRNA alteration in OLP was found in a small group of patients with relative shorter duration of disease - 6.2 years compared with 10.7 years for whole group of patients (54). Our contradictory finding that longer duration of disease yielded higher methylation frequency may be due the short follow-up period (5.6 years) in general for patients involved in present study.

Overall, our findings suggest that promoter methylation of p16 and miR-137 is relatively common event in OSCC and, to a somewhat lower extent, in OLP. In addition, the exclusivity of methylation in the epithelium from patients with OLP indicates that the abnormal methylation of $p 16$ and miR-137 may represent an early alteration during the malignancy and may preserve a potential to serve as biomarker for early malignant prediction for patients with OLP. However, further follow-up studies may be needed to evaluate its prediction power in clinic. Furthermore, we have found several risk factors including aging that are associated with aberrant methylation of $p 16$ and $m i R-137$. In this way, our current finding added in novel information for the malignant potential in OLP.

\section{References}

1. Van der Waal I. Potentially malignant disorders of the oral and oropharyngeal mucosa; terminology, classification and present concepts of management. Oral Oncol 2009; 45: 317-23.

2. Farhi D, Dupin N. Pathophysiology, etiologic factors, and clinical management of oral lichen planus, part I: facts and controversies. Clin Dermatol 2010; 28: 100-8.

3. Eisenberg E. Oral lichen planus: a benign lesion. J Oral Maxillofac Surg 2000; 58: 1278-85.

4. Gonzalez-Moles MA, Scully C, Gil-Montoya JA. Oral lichen planus: controversies surrounding malignant transformation. Oral Dis 2008; 14: 229-43.

5. Lodi G, Scully C, Carrozzo M, Griffiths M, Sugerman PB, Thongprasom K. Current controversies in oral lichen planus: report of an international consensus meeting. Part 2. Clinical management and malignant transformation. Oral Surg Oral Med Oral Pathol Oral Radiol Endod 2005; 100: 164-78.

6. Laeijendecker R, Van Joost T, Kuizinga MC, Tank B, Neumann HAM. Premalignant nature of oral lichen planus. Acta Derm Venereol 2005; 85: 516-20.
7. Mignogna MD, Fedele S, Lo Russo L. Dysplasia/neoplasia surveillance in oral lichen planus patients: a description of clinical criteria adopted at a single centre and their impact on prognosis. Oral Oncol 2006; 42: 819-24.

8. Carbone M, Arduino PG, Carrozzo M, et al. Course of oral lichen planus: a retrospective study of 808 northern Italian patients. Oral Dis 2009; 15: 235-43.

9. Bombeccari GP, Guzzi G, Tettamanti M, et al. Oral lichen planus and malignant transformation: a longitudinal cohort study. Oral Surg Oral Med Oral Pathol Oral Radiol Endod 2011; 112: 328-34.

10. Monk M. Epigenetic programming of differential gene expression in development and evolution. Dev Genet 1995; 17: $188-97$.

11. Herman JG, Merlo A, Mao L, et al. Inactivation of the CDKN2/p16/MTS1 gene is frequently associated with aberrant DNA methylation in all common human cancers. Cancer Res 1995; 55: 4525-30.

12. Gonzalez-Zulueta M, Bender CM, Yang AS, et al. Methylation of the $5^{\prime} \mathrm{CpG}$ island of the p16/CDKN2 tumor suppressor gene in normal and transformed human tissues correlates with gene silencing. Cancer Res 1995; 55: 4531-5.

13. Diez-Perez R, Campo-Trapero J, Cano-Sanchez J, et al. Methylation in oral cancer and pre-cancerous lesions (Review). Oncol Rep 2011; 25: 1203-9.

14. Gao S, Nielsen BS, Krogdahl A, et al. Epigenetic alterations of the SERPINE1 gene in oral squamous cell carcinomas and normal oral mucosa. Genes Chromosom Cancer 2010; 49: 526 -38 .

15. Demokan S, Chuang A, Suoglu Y, et al. Promoter methylation and loss of p16(INK4a) gene expression in head and neck cancer. Head Neck 2012; 34: 1470-5.

16. Liu HW, Hu BQ, Cao CF. [The p16 methylation in oral leukoplakia and oral squamous cell carcinoma]. Zhonghua Kou Qiang Yi Xue Za Zhi 2005; 40: 94-7.

17. Hall GL, Shaw RJ, Field EA, et al. p16 Promoter methylation is a potential predictor of malignant transformation in oral epithelial dysplasia. Cancer Epidemiol Biomarkers Prev 2008; 17: 2174-9.

18. Cao J, Zhou J, Gao Y, et al. Methylation of p16 CpG island associated with malignant progression of oral epithelial dysplasia: a prospective cohort study. Clin Cancer Res 2009; 15: $5178-83$.

19. Kozaki K, Imoto I, Mogi S, Omura K, Inazawa J. Exploration of tumor-suppressive microRNAs silenced by DNA hypermethylation in oral cancer. Cancer Res 2008; 68: 2094-105.

20. Cimmino A, Calin GA, Fabbri M, et al. miR-15 and miR-16 induce apoptosis by targeting BCL2. Proc Natl Acad Sci USA 2005; 102: 13944-9.

21. Mitra S, Das S, Ghosal S, Chakrabarti J. HNOCDB: a comprehensive database of genes and miRNAs relevant to head and neck and oral cancer. Oral Oncol 2012; 48: 117-19.

22. Wu BH, Xiong XP, Jia J, Zhang WF. MicroRNAs: new actors in the oral cancer scene. Oral Oncol 2011; 47: 314-19.

23. Scapoli L, Palmieri A, Lo Muzio L, et al. MicroRNA expression profiling of oral carcinoma identifies new markers of tumor progression. Int J Immunopathol Pharmacol 2010; 23: $1229-34$.

24. Henson BJ, Bhattacharjee S, O'Dee DM, Feingold E, Gollin $\mathrm{SM}$. Decreased expression of miR-125b and miR-100 in oral cancer cells contributes to malignancy. Genes Chromosom Cancer 2009; 48: 569-82.

25. Ando T, Yoshida T, Enomoto S, et al. DNA methylation of microRNA genes in gastric mucosae of gastric cancer patients: its possible involvement in the formation of epigenetic field defect. Int J Cancer 2009; 124: 2367-74. 
26. Bandres E, Agirre X, Bitarte N, et al. Epigenetic regulation of microRNA expression in colorectal cancer. Int J Cancer 2009; 125: $2737-43$.

27. Langevin SM, Stone RA, Bunker CH, Grandis JR, Sobol RW, Taioli E. MicroRNA-137 promoter methylation in oral rinses from patients with squamous cell carcinoma of the head and neck is associated with gender and body mass index. Carcinogenesis 2010; 31: 864-70.

28. Wiklund ED, Gao S, Hulf T, et al. MicroRNA alterations and associated aberrant DNA methylation patterns across multiple sample types in oral squamous cell carcinoma. PLOS ONE 2011; 6: e27840.

29. Danielsson K, Wahlin YB, Gu X, Boldrup L, Nylander K. Altered expression of miR-21, miR-125b, and miR-203 indicates a role for these microRNAs in oral lichen planus. J Oral Pathol Med 2012; 41: 90-5.

30. Kramer IR, Lucas RB, Pindborg JJ, Sobin LH. Definition of leukoplakia and related lesions: an aid to studies on oral precancer. Oral Surg Oral Med Oral Pathol 1978; 46: 518-39.

31. Mackenzie IC, Dabelsteen E, Roed-Petersen B. A method for studying epithelial-mesenchymal interactions in human oral mucosal lesions. Scand J Dent Res 1979; 87: 234-43.

32. Clark SJ, Harrison J, Paul CL, Marianne F. High sensitivity mapping of methylated cytosines. Nucleic Acids Res 1994; 22: 2990-7.

33. Hallopeu H. Surun cas de Wilson gingival avec neoplasic voisine dans la region maxillaire. Bull Soc Fr Dermatol Syphiligr 1910; 17: 3.

34. Thode C, Bilde A, Von Buchwald C, Dabelsteen E. TP53 mutations in clinically normal mucosa adjacent to oral carcinomas. J Oral Pathol Med 2010; 39: 662-6.

35. Gao S, Worm J, Guldberg P, et al. Genetic and epigenetic alterations of the blood group $\mathrm{ABO}$ gene in oral squamous cell carcinoma. Int J Cancer 2004; 109: 230-7.

36. Gao S, Worm J, Guldberg P, et al. Loss of heterozygosity at 9q33 and hypermethylation of the DBCCR1 gene in oral squamous cell carcinoma. Br J Cancer 2004; 91: 760-4.

37. Safadi RA, Al Jaber SZ, Hammad HM, Hamasha AAH. Oral lichen planus shows higher expressions of tumor suppressor gene products of p53 and p21 compared to oral mucositis. An immunohistochemical study. Arch Oral Biol 2010; 55: 45461.

38. Kamb A, Gruis NA, Weaver-Feldhaus J, et al. A cell cycle regulator potentially involved in genesis of many tumor types. Science 1994; 264: 436-40.

39. Feinberg AP, Tycko B. The history of cancer epigenetics. Nat Rev Cancer 2004; 4: 143-53.

40. Huang LW, Pan HS, Lin YH, Seow KM, Chen HJ, Hwang JL. P16 methylation is an early event in cervical carcinogenesis. Int J Gynecol Cancer 2011; 21: 452-6.

41. Wang D, Wang J, Li Y, He ZL, Zhang Y. The influence of anthracosis and p16 ink4a gene aberrant methylation on smallsized pulmonary adenocarcinoma. Exp Mol Pathol 2011; 90: 131-6.

42. Buajeeb W, Poomsawat S, Punyasingh J, Sanguansin S. Expression of p16 in oral cancer and premalignant lesions. J Oral Pathol Med 2009; 38: 104-8.

43. Snietura M, Jaworska M, Piglowski W, Goraj-Zajac A, Wozniak G, Lange D. High-risk HPV DNA status and p16 (INK4a) expression as prognostic markers in patients with squamous cell cancer of oral cavity and oropharynx. Pol J Pathol 2010; 61: 133-9.

44. Jablonowski Z, Reszka E, Gromadzinska J, Wasowicz W, Sosnowski M. Hypermethylation of p16 and DAPK promoter gene regions in patients with non-invasive urinary bladder cancer. Arch Med Sci 2011; 7: 512-16.
45. Shin $\mathrm{KC}$, Lee $\mathrm{KH}$, Lee $\mathrm{CH}$, Shin $\mathrm{IH}$, Suh HS, Jeon $\mathrm{CH}$. MAGE A1-A6 RT-PCR and MAGE A3 and p16 methylation analysis in induced sputum from patients with lung cancer and non-malignant lung diseases. Oncol Rep 2012; 27: 911-16.

46. Radisky DC, Santisteban M, Berman HK, et al. p16(INK4a) expression and breast cancer risk in women with atypical hyperplasia. Cancer Prev Res (Phila) 2011; 4: 1953-60.

47. Kresty LA, Mallery SR, Knobloch TJ, et al. Alterations of p16 (INK4a) and p14(ARF) in patients with severe oral epithelial dysplasia. Cancer Res 2002; 62: 5295-300.

48. Rentoft M, Fahlen J, Coates PJ, et al. miRNA analysis of formalin-fixed squamous cell carcinomas of the tongue is affected by age of the samples. Int J Oncol 2011; 38: 61-9.

49. Chang SS, Jiang WW, Smith I, et al. MicroRNA alterations in head and neck squamous cell carcinoma. Int J Cancer 2008; 123: $2791-7$.

50. Volinia S, Calin GA, Liu CG, et al. A microRNA expression signature of human solid tumors defines cancer gene targets. Proc Natl Acad Sci USA 2006; 103: 2257-61.

51. Cervigne NK, Reis PP, Machado J, et al. Identification of a microRNA signature associated with progression of leukoplakia to oral carcinoma. Hum Mol Genet 2009; 18: 4818-29.

52. Arao TC, Guimaraes AL, De Paula AM, Gomes CC, Gomez RS. Increased miRNA-146a and miRNA-155 expressions in oral lichen planus. Arch Dermatol Res 2011; 304: 371-5.

53. Zhang WY, Liu W, Zhou YM, Shen XM, Wang YF, Tang GY. Altered microRNA expression profile with miR-27b down-regulation correlated with disease activity of oral lichen planus. Oral Dis 2012; 18: 265-70.

54. Nylander E, Ebrahimi M, Wahlin YB, Boldrup L, Nylander K. Changes in miRNA expression in sera and correlation to duration of disease in patients with multifocal mucosal lichen planus. J Oral Pathol Med 2012; 41: 86-9.

55. Balaguer F, Link A, Lozano JJ, et al. Epigenetic silencing of miR-137 is an early event in colorectal carcinogenesis. Cancer Res 2010; 70: 6609-18.

56. Issa JP, Vertino PM, Boehm CD, Newsham IF, Baylin SB. Switch from monoallelic to biallelic human IGF2 promoter methylation during aging and carcinogenesis. Proc Natl Acad Sci USA 1996; 93: 11757-62.

57. Zheng QH, Ma LW, Zhu WG, Zhang ZY, Tong TJ. p21Waf1/ Cip1 plays a critical role in modulating senescence through changes of DNA methylation. J Cell Biochem 2006; 98: 123048.

58. Lanceta J, Prough RA, Liang R, Wang E. MicroRNA gorup disorganization in aging. Exp Gerontol 2010; 45: 269-78.

59. Grillari J, Hackl M, Grillari-Voglauer R. miR-17-92 cluster ups and downs in cancer and aging. Biogerontology 2010;11: 501-6.

60. Leal MF, Lima EM, Silva PN, et al. Promoter hypermethylation of CDH1, FHIT, MTAP and PLAGL1 in gastric adenocarcinoma in individuals from Northern Brazil. World $J$ Gastroenterol 2007; 13: 2568-74.

61. Lind GE, Thorstensen L, Lovig T, et al. A CpG island hypermethylation profile of primary colorectal carcinomas and colon cancer cell lines. Mol Cancer 2004; 3: 28.

62. Vaissiere T, Hung RJ, Zaridze D, et al. Quantitative analysis of DNA methylation profiles in lung cancer identifies aberrant DNA methylation of specific genes and its association with gender and cancer risk factors. Cancer Res 2009; 69: 243-52.

63. Kikuchi S, Yamada D, Fukami T, et al. Hypermethylation of the TSLC1/IGSF4 promoter is associated with tobacco smoking and a poor prognosis in primary nonsmall cell lung carcinoma. Cancer 2006; 106: 1751-8.

64. Lai JC, Cheng YW, Chiou HL, Wu MF, Chen CY, Lee H. Gender difference in estrogen receptor alpha promoter 
hypermethylation and its prognostic value in non-small cell lung cancer. Int J Cancer 2005; 117: 974-80.

65. Langevin SM, Stone RA, Bunker CH, et al. MicroRNA-137 promoter methylation is associated with poorer overall survival in patients with squamous cell carcinoma of the head and neck. Cancer 2011; 117: 1454-62.

66. Enokida H, Shiina H, Urakami S, et al. Smoking influences aberrant $\mathrm{CpG}$ hypermethylation of multiple genes in human prostate carcinoma. Cancer 2006; 106: 79-86.

67. Marsit CJ, Karagas MR, Únaee H, et al. Carcinogen exposure and gene promoter hypermethylation in bladder cancer. Carcinogenesis 2006; 27: 112-16.
68. Kitano K, Watanabe K, Emoto N, et al. CpG island methylation of microRNAs is associated with tumor size and recurrence of non-small-cell lung cancer. Cancer Sci 2011; 102: $2126-31$.

69. Meng F, Glaser SS, Francis H, et al. Epigenetic Regulation of miR-34a Expression in Alcoholic Liver Injury. Am J Pathol 2012; 181: 804-17.

\section{Acknowledgement}

This study was supported by Military Medical Research Fund (08G105), China. 